\title{
Regorafenib or Cabozantinib in second or subsequent lines after Sorafenib in advanced hepatocellular carcinoma. Which way to chose?
}

\author{
Jacopo Giuliani ${ }^{1 *}$, Francesco Fiorica ${ }^{2}$ and Andrea Bonetti ${ }^{1}$ \\ ${ }^{1}$ Department of Oncology, Mater Salutis Hospital, Italy \\ ${ }^{2}$ Department of Radiation Oncology, Mater Salutis Hospital, Italy
}

\begin{abstract}
The aim of this paper is to assess the cost-effectivess of regorafenib and cabozantib in the treatment of advanced hepatocellular carcinoma (HCC) after sorafenib. Pivotal phase III randomized controlled trials (RCTs) were considered. Incremental cost-effectiveness ratio (ICER) was calculated for both treatments. Two phase III RCTs, including 1274 patients, were considered. Regorafenib resulted the less expensive, with $2771 €$ per month overall survival (OS)-gained versus $5309 €$ of cabozantinib. Combining pharmacological costs of drugs with the measure of efficacy represented by the OS, regorafenib is a cost-effective for the treatment of advanced HCC after sorafenib.
\end{abstract}

\section{Introduction}

Recently, the introduction of cabozantinib, a tyrosine kinase inhibitor, offered a therapeutic possibility beyond the first or subsequentline for patients affected by advanced hepatocellular carcinoma (HCC) in progression after sorafenib, with the improvement in clinical outcomes and prolonged survival [1]. This therapeutical option in this setting of advanced HCC adds to regorafenib, a small-molecule multikinase inhibitor, that improved overall survival (OS) in the pivotal phase III randomized controlled trial (RCT) [2]. The introduction of these active new agents raises the main problem of pharmacy costs increase. The aim of this paper is to assess the cost-effectiveness of regorafenib and cabozantib in the treatment of advanced HCC.

\section{Materials and methods}

Pivotal phase III RCTs of regorafenib and cabozantinib in the treatment of advanced HCC after sorafenib in second or subsequent lines were considered. Incremental cost-effectiveness ratio (ICER) was calculated as the ratio between the difference of the costs in the intervention and in the control groups (pharmacy costs) and the difference between the effect in the intervention and in the control groups (OS). The costs of drugs are at the Pharmacy of our Hospital and are expressed in euros $(€)$, updated to June 2020. Calculations were based on an "ideal patient" (BSA $1.8 \mathrm{sqm}$; weight $70 \mathrm{Kg}$ ). The dosage of drugs were considered according to those reported in each RCT. We assumed the following costs for each month of therapy: regorafenib= $1940 €$ (at the dose of $160 \mathrm{mg} /$ daily for the first 3 weeks of each 4 -week cycle), cabozantinib $=2920 €$ (same price for $60 \mathrm{mg}, 40 \mathrm{mg}$ and $20 \mathrm{mg}$ ). European Society for Medical Oncology Magnitude of Clinical Benefit Scale (ESMO-MCBS) [3] was applied to the above RCTs to derive a relative ranking of clinical benefit [4].

\section{Results}

Two phase III RCTs, including 1274 patients, were considered. The main reported outcomes of the analyzed phase III RCTs are reported in table 1. ESMO-MCBS (Table 1) reached grade 3 for RESORCE trial [2] and grade 2 for the CELESTIAL trial [2]. Regorafenib resulted the less expensive, with $2771 €$ per month OS-gained (Table 1).

\section{Discussion}

Two main variables are able to condition pharmacy costs: the efficacy of treatment and the price of drugs. The first variable is related to the patient's inclusions criteria and we know that results from RCTs could be not representative of daily clinical practice (that is of patients treated outside such trials). The price of drugs is the second strong variable $[5,6]$.

In addition, the annual perspective of the annual cost of treatment wit regorafenib (33 $252 €$ ) is in line with those reported in literature, that found a favored implementing intervention for thresholds of less than $\$ 61,500$ (57 $138 €$ ) per life-year gained [7], differently from cabozantinib (63708€).

However, to our knowledge, this is the first time an analysis of the pharmacological costs of advanced HCC treated with regorafenib or cabozantinib after sorafenib is linked to OS.

The results become even more interesting if we consider that $51 \%$ of patients in the RESORCE trial [3] and 62\% in the CELESTIAL trial [2] have reduced the full dose of regorafenib and cabozantinib, respectively. In facts, while in the case of cabozantinib the dose reduction does not impact on pharmacy costs (flat price, that means the same price for the

*Correspondence to: Jacopo Giuliani, Department of Oncology, Mater Salutis Hospital, Az. ULSS 9 Scaligera. Via Gianella 1-37045 Legnago (VR), Italy, Tel: ++39-0442622801, Fax: ++39-0442622469, E-mail: giuliani.jacopo@alice.it

Key words: HCC, regorafenib, cabozantinib, cost of drugs

Received: September 03, 2020; Accepted: September 24, 2020; Published: September 27, 2020 
Table 1. Pharmacological costs and difference in OS with regorafenib and cabozantinib in advanced HCC after sorafenib.

\begin{tabular}{|c|c|c|c|c|c|c|c|c|c|c|c|c|}
\hline Authors/Trial & $\begin{array}{l}\text { Comparative } \\
\text { Regimens }\end{array}$ & $\begin{array}{l}\text { Total N } \\
\text { patients }\end{array}$ & $\begin{array}{l}\text { Primary } \\
\text { endpoint }\end{array}$ & $\begin{array}{l}\text { OS } \\
\text { (months) }\end{array}$ & p-value & $\begin{array}{l}\text { OS gain } \\
\text { (months) }\end{array}$ & $\begin{array}{l}\text { OS HR } \\
\text { (95\% C.I.) }\end{array}$ & $\begin{array}{l}\text { ESMO- } \\
\text { MCBS }\end{array}$ & $\begin{array}{l}\text { Median duration } \\
\text { of treatment } \\
\text { (months) }\end{array}$ & $\begin{array}{l}\text { Costs of } \\
\text { therapy }(\epsilon)\end{array}$ & $\begin{array}{l}\text { Difference } \\
\text { in costs }(\boldsymbol{\epsilon})\end{array}$ & $\operatorname{ICER}(\epsilon)$ \\
\hline \multirow{2}{*}{$\begin{array}{l}\text { Bruix et al. [3] } \\
\text { RESORCE }\end{array}$} & regorafenib & 374 & \multirow{2}{*}{ OS } & 10.6 & \multirow{2}{*}{$<0.001$} & \multirow{2}{*}{2.8} & \multirow{2}{*}{$\begin{array}{l}0.63 \\
(0.50-0.79)\end{array}$} & \multirow{2}{*}{3} & 3.6 & 7760 & \multirow{2}{*}{7760} & \multirow{2}{*}{$\begin{array}{l}2771^{\mathrm{a}} \\
2078^{\mathrm{b}} \\
1385^{\mathrm{c}}\end{array}$} \\
\hline & placebo & 193 & & 7.8 & & & & & 1.9 & 0 & & \\
\hline \multirow{2}{*}{$\begin{array}{l}\text { Abou-Alfa et al. [1] } \\
\text { CELESTIAL }\end{array}$} & cabozantinib & 470 & \multirow{2}{*}{ OS } & 10.2 & \multirow{2}{*}{0.005} & \multirow{2}{*}{2.2} & \multirow{2}{*}{$\begin{array}{l}0.76 \\
(0.63-0.92)\end{array}$} & \multirow{2}{*}{2} & 3.8 & 11680 & \multirow{2}{*}{11680} & \multirow{2}{*}{5309} \\
\hline & placebo & 237 & & 8.0 & & & & & 2.0 & 0 & & \\
\hline
\end{tabular}

Legend: N: Number; OS: Overall Survival; ESMO-MCBS: European Society for Medical Oncology-Magnitude of Clinical Benefit Scale (from grade 1 to grade 5); ICER: Incremental Cost-Effectiveness Ratio (expressed as the difference ( $€$ ) per month-OS gained); ${ }^{\text {a }}$ : at the dose of $160 \mathrm{mg} / \mathrm{daily}$ for the first 3 weeks of each 4 -week cycle; ${ }^{\text {b}}$ : with dose reduction at $120 \mathrm{mg} /$ daily for the first 3 weeks of each 4-week cycle; c: with dose reduction at $80 \mathrm{mg} /$ daily for the first 3 weeks of each 4-week cycle.

Table 2. A comparison between regorafenib and cabozantinib in advanced HCC with the costs of immune check point inhibitors (ICIs, nivolumab, pembrolizumab and atezolizumab) in the treatment of advanced NSCLC and the costs of the reference elements in international markets (gold, platinum).

\begin{tabular}{|l|l|l|l|}
\hline Element/drug & Cost per gram $(\boldsymbol{\epsilon})$ & $\begin{array}{l}\Delta \text { toward gold 18K } \\
\text { per gram }(\boldsymbol{(})\end{array}$ & $\begin{array}{l}\Delta \text { toward platinum } \\
\mathbf{1 8 K} \text { per gram }(\boldsymbol{(})\end{array}$ \\
\hline gold $18 \mathrm{~K}$ & 46.90 & -- & -- \\
\hline platinum & 21.45 & -- & -- \\
\hline regorafenib & 577.25 & 530.35 & 555.80 \\
\hline & $1733.33^{\mathrm{a}}$ & $1686.43^{\mathrm{a}}$ & $1711.88^{\mathrm{a}}$ \\
\hline cabozantinib & $2600.00^{\mathrm{b}}$ & $2553.10^{\mathrm{b}}$ & $2578.55^{\mathrm{b}}$ \\
\hline nivolumab & $5200.00^{\mathrm{c}}$ & $5153.10^{\mathrm{c}}$ & $5178.55^{\mathrm{c}}$ \\
\hline pembrolizumab & 107500.00 & 107453.10 & 107478.55 \\
\hline atezolizumab & 205608.00 & 205561.10 & 205586.55 \\
\hline & 1726.03 & 1680.87 & 1697.50 \\
\hline
\end{tabular}

Legend: k: Karat; nivolumab: $1070.00 €$ for $100 \mathrm{mg}$, pembrolizumab: $2056.08 €$ for 100 $\mathrm{mg}$, atezolizumab $=2071.24 €$ for $1200 \mathrm{mg}$.

different dosages), in the case of regorafenib it implies for a reduction on pharmacy costs of $25 \%$ and $50 \%$ if we consider the dose reduction at $120 \mathrm{mg} /$ daily and $80 \mathrm{mg} /$ daily, respectively (Table 1 ).

In addition, we have to consider that the scenario in the advanced HCC is changing, with the recently introduction in first-line of Lenvatinib [8] and the combination of atezolizumab and bevacizumab [9]. So, regorafenib and cabozantinib will be placed in third line (about $30 \%$ of patients treated with cabozantinib in pivotal phase III RCT where already in third line [1]. Ramucirumab was not considered in our analysis because it was approved by Food and Drug Administration (FDA) in 2019, but not by European Medical Agency (EMA) [10].

We have also compare the pharmacy cost of regorafenib and cabozantinib with the pharmacy costs of immune check point inhibitors (ICIs), (nivolumab, pembrolizumab and atezolizumab) registered in other tumors (eg. non-small cell lung cancer (NSCLC), head and neck carcinoma, urological malignancies) and known as the most expensive new drugs in medical oncology ${ }^{11-16}$, with the costs of the reference elements in international markets, gold 18 karat $(\mathrm{K})$ and platinum. Both regorafenib and cabozantinib have a high cost per gram (even if significantly lower than most ICIs), with $577.25 €$ (regorafenib), $1733.33 €$ (cabozantinib, $60 \mathrm{mg}$ tablets), $2600.00 €$ (cabozantinib, $40 \mathrm{mg}$ tablets) and $5200.00 €$ (cabozantinib, $20 \mathrm{mg}$ tablets), with a $\Delta$ toward gold $18 \mathrm{~K}$ and platinum per gram of $530.35 €$ and $555.80 €$ for regorafenib, respectively and of $1686.43 €$ (600 mg tablets), $2553.10 €$ (40 mg tablets) and $5153.10 €(20 \mathrm{mg}$ tablets) and $1711.88 €(60 \mathrm{mg}$ tablets), $2578.55 €$ ( $40 \mathrm{mg}$ tablets) and $5178.55 €(20 \mathrm{mg}$ tablets) for cabozantinib, respectively. So, a reduction in pharmacological costs is mandatory if we want to consider targeted agents more advantageous in terms of cost-effectiveness.

In conclusion, based on ICER, regorafenib is a cost-effective for the treatment of advanced HCC after sorafenib. The price of newly registered oncologic drugs is continuously increasing posing a serious treat to the sustainability of the National Health Systems, especially in Countries in which the public control and oversight over the prices is limited. Medical Oncologists and the society as a whole are becoming more and more concerned with the issues of the costs of the cure of cancer patients and are able to bring attention to the "just price" of new treatments that must reflect the reality of their true benefits and societal and personal costs.

\section{Conflict of Interest statement}

The authors have no relevant affiliations or financial involvement with any organization or entity with a financial interest in or financial conflict with the subject matter or materials discussed in the manuscript. This includes employment, consultancies, honoraria, stock ownership or options, expert testimony, grants or patents received or pending, or royalties.

Research involving human participants and/or animals: No human participants and/or animals were involved.

Authors' contributions: All Authors contributed equally to (1) conception and design, acquisition of data, or analysis and interpretation of data; (2) drafting the article and revising it critically for important intellectual content; and (3) final approval of the version to be published.

\section{References}

1. Abou-Alfa GK, Meyer T, Cheng AL, El-Khoueiry AB, Rimassa L, et al. (2018) Cabozantinib in Patients With Advanced and Progressing Hepatocellular Carcinoma. N Engl J Med 379: 54-63. [Crossref]

2. Bruix J, Qin S, Merle P, Granito A, RESORCE Investigators, et al. (2017) Regorafenib for Patients With Hepatocellular Carcinoma Who Progressed on Sorafenib Treatment (RESORCE): A Randomised, Double-Blind, Placebo-Controlled, Phase 3 Trial. Lancet 389: 56-66. [Crossref]

3. Cherny NI, Sullivan R, Dafni U, Kerst JM, Sobrero A, et al. (2015) A standardised, generic, validated approach to stratify the magnitude of clinical benefit that can be anticipated from anti-cancer therapies: the European Society for Medical Oncology Magnitude of Clinical Benefit Scale (ESMO-MCBS). Ann Oncol 26: 1547-1573. [Crossref]

4. Giuliani J, Bonetti A (2018) Which grade is of clinical benefit in the randomised controlled trials? The example of 54th American Society of Clinical Oncology annual meeting, Eur J Cancer 104: 233-235. [Crossref]

5. Olchanski N, Zhong Y, Cohen JT, Saret C, Bala M, et al. (2015) The peculiar economics of life-extending therapies: a review of costing methods in health economic evaluations in oncology. Expert Rev Pharmacoecon Outcomes Res 15: 931-940. [Crossref]

6. Cohn DE, Kim KH, Resnick KE, O'Malley DM, Straughn JM Jr. (2011) At what cost does a potential survival advantage of bevacizumab make sense for the primary treatment of ovarian cancer? A cost-effectiveness analysis. J Clin Oncol 29: 1247-1251. [Crossref]

7. Azimi NA, Welch HG (1998) The effectiveness of cost-effectiveness analysis in containing costs. J Gen Intern Med 13: 664. [Crossref] 
Giuliani J (2020) Regorafenib or Cabozantinib in second or subsequent lines after Sorafenib in advanced hepatocellular carcinoma. Which way to chose?

8. Kudo M, Finn RS, Qin S, Han KH, Ikeda K, et al. (2018) Lenvatinib Versus Sorafenib in First-Line Treatment of Patients With Unresectable Hepatocellular Carcinoma: A Randomised Phase 3 Non-Inferiority Trial. Lancet 391: 1163-1173. [Crossref]

9. Finn RS, Qin S, Ikeda M, Galle PR, IMbrave150 Investigators (2002) Atezolizumab Plus Bevacizumab in Unresectable Hepatocellular Carcinoma. N Engl J Med 382: 1894-1905. [Crossref]

10. Zhu AX, Kang YK, Yen CJ, Finn RS, REACH-2 study investigators (2019) Ramucirumab After Sorafenib in Patients With Advanced Hepatocellular Carcinoma and Increased $\alpha$-fetoprotein Concentrations (REACH-2): A Randomised, DoubleBlind, Placebo-Controlled, Phase 3 Trial. Lancet Oncol 20 :282-96. [Crossref]

11. Giuliani J, Bonetti A (2019) Financial Toxicity and Non-small Cell Lung Cancer Treatment: The Optimization in the Choice of Immune Check Point Inhibitors. Anticancer Res 39: 3961-3965. [Crossref]
12. Giuliani J, Bonetti A (2019) Immunotherapy in first-line for advanced non-small cell lung cancer: A cost-effective choice? Recenti Prog Med 110: 138-143. [Crossref]

13. Giuliani J, Bonetti A (2019) Immune-checkpoint inhibitors in head and neck squamous cell carcinoma: cost-efficacy in second-line treatment based on programmed deathligand 1 (PD-L1) level. Oral Oncol 97: 143-145. [Crossref]

14. Giuliani J, Bonetti A (2017) Nivolumab in Second-Line Treatment for Advanced NonSmall-Cell Lung Cancer With Squamous-Cell Histology: A Perspective Based on Pharmacologic Costs. Clin Lung Cancer 18: e363-e365. [Crossref]

15. Giuliani J, Bonetti A (2018) Nivolumab Is a Cost-Effective Second-Line Treatment for Metastatic Renal-Cell Carcinoma. Clin Genitourin Cancer 16: e557-562. [Crossref]

16. Giuliani J, Albanese V, Ponturo G, Bonetti A (2019) Economic sustainability of nivolumab at flat dose for second-line treatment of metastatic non-small cell lung cancer in real life. J Oncol Pharm Pract 25: 2059-2060. [Crossref]

Copyright: $\odot 2020$ Giuliani J. This is an open-access article distributed under the terms of the Creative Commons Attribution License, which permits unrestricted use, distribution, and reproduction in any medium, provided the original author and source are credited. 